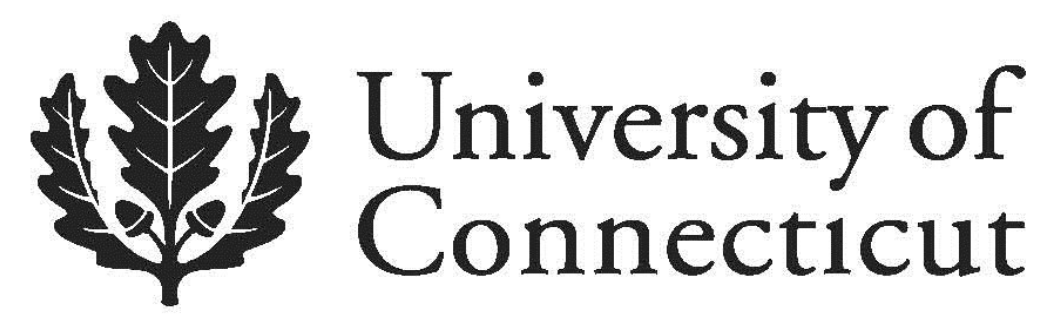

Department of Economics Working Paper Series

\title{
Transaction-Specific Investments and Organizational Choice: A Coase-to-Coase Theory
}

Thomas J. Miceli

University of Connecticut

Working Paper 2014-06

March 2014

365 Fairfield Way, Unit 1063

Storrs, CT 06269-1063

Phone: (860) 486-3022

Fax: (860) 486-4463

http://www.econ.uconn.edu/

This working paper is indexed on RePEc, http://repec.org 


\title{
Transaction-Specific Investments and Organizational Choice: A Coase-to-Coase Theory
}

\author{
by
}

Thomas J. Miceli*

\begin{abstract}
This paper examines markets, firms, and the law as alternative institutional arrangements for organizing transactions that involve transaction-specific investments and uncertain performance. The analysis is the logical extension of Coase's seminal analysis of the market-firm boundary on one hand, and the market-law boundary on the other. It thus combines insights from the literature on industrial organization and law and economics. The result is a unified framework that reveals the relative advantages and disadvantages, within a fairly simple economic setting, of market exchange, court ordering (contracts), and internal governance (agency).
\end{abstract}

Key words: Asset specificity, contracts, firms, holdup problem, market exchange JEL codes: D23, K12, L14, L22

March 2014

*Professor, Department of Economics, University of Connecticut, Storrs, CT 062691063; Ph: (860) 486-5810; Fax: (860) 486-4463; e-mail: Thomas.Miceli@ UConn.edu. In writing this paper I have benefited from conversations with Richie Adelstein, and also from the helpful comments of Dick Langlois and students in the undergraduate honors seminar in the economics department at the University of Connecticut. 


\section{Transaction-Specific Investments and Organizational Choice: A Coase-to-Coase Theory}

\section{Introduction}

Beginning with Coase's (1937) seminal paper, a large literature has arisen to examine the boundary between the market and the firm. ${ }^{1}$ The key question addressed by this literature concerns whether, or under what conditions, it is more efficient to organize a transaction through the market or within the confines of a firm. A point that has not often been made, however, is that there are different ways in which market (arm's-length) transactions can be organized. One possibility is a spot transaction in which the parties meet and negotiate an instantaneous exchange under certainty; another is a contractual arrangement that is negotiated before all information pertinent to the transaction is known. The advantage of a contract is that it allows commitments to be made that are enforceable by a third party (the court), thereby avoiding holdup problems. ${ }^{2}$ (This form of governance is therefore sometimes referred to as "court ordering.") The disadvantage is that the terms must be negotiated under uncertainty, thus leading to the possibility of costly litigation once the information is revealed.

In examining this trade-off, it will be useful to recognize that a contract is intermediate between a pure market transaction, where enforcement is not an issue, and a transaction within a firm, where the owner (residual claimant) can dictate the terms of the transaction. In this light, one way to think of the contract is that a court stands ready to enforce the terms of the transaction, much the way the owner of a firm could, but unlike

\footnotetext{
${ }^{1}$ See, for example, Williamson $(1975,1979,1987)$, Klein, Crawford and Alchian (1978), Grossman and Hart (1986), and Hart and Moore (1988, 1990). For a recent survey, see Hart (2011).

${ }^{2}$ On the holdup problem, see the references in footnote 1, as well as Goldberg $(1976,1985)$, Edlin and Reichelstein (1996), Segal (1999), and Bolton and Dewatripont (2005, pp. 560-578).
} 
the firm owner, the court has no financial stake in the transaction and only acts when called on. The law therefore provides temporary access to coercion when a dispute arises in the face of unforeseen circumstances, and in this sense courts can be thought of as acting like a "temporary firm." This perspective reflects the boundary between pure market exchange and exchange by means of legally enforceable contracts, which is, of course, the general subject of Coase's other classic paper on social cost (Coase, 1960). ${ }^{3}$ By recognizing the boundary between markets and contracts on one hand, and between markets and firms one the other, the current paper therefore blends the insights from Coase's two classic papers in an effort to provide a more complete picture of the organization of exchange. Figure 1 depicts the logically complete framework, which therefore involves a third boundary: that between firms and contracts. The distinction here, as will be made clear below, is between fully coercive exchange within the boundaries of a firm, and consensual exchange outside of the firm that is enforceable ondemand by the court, which, as noted, potentially introduces a non-consensual element into the transaction.

\section{[Figure 1 here]}

In examining the choice among these three options, the formal analysis focuses on two key factors. The first concerns the incentives for parties to make efficient transaction-specific investments prior to exchange, which has been the subject of much of Williamson's work on the advantage of firms and contracts over market exchange. The second concerns incentives for efficient performance of a transaction - that is, deciding

\footnotetext{
${ }^{3}$ Also see the analysis of the choice between property rules and liability rules in the seminal paper by Calabresi and Melamed (1972), which reflects the same distinction. Specifically, property rules represent consensual exchange in a market setting, where the role of the court is simply to protect underlying property rights, whereas liability rules represent non-consensual exchange on terms set by the court.
} 
when the transaction should be completed and when it should be breached, which has been the subject of much of the law and economics literature on contract breach. ${ }^{4}$ The next section motivates the analysis by describing an illustrative case from contract law.

\section{An illustrative case}

Consider the well-known case of Goebel v. Linn, ${ }^{5}$ which involved a dispute between an ice company and a brewery that arose when the ice company refused to deliver ice at the contractually set price of $\$ 2$ a ton because an unusually warm winter had caused the ice "crop" to fail. The brewery, which had a large stock of beer on hand that would have spoiled without ice, therefore agreed to increase the price to $\$ 3.50$ per ton and took delivery, but later sued to have the original price reinstated by the court. ${ }^{6}$ The court, however, enforced the higher price based on the "unexpected and extraordinary circumstances" that had arisen, ${ }^{7}$ which likely would have driven the ice company into bankruptcy had the lower price prevailed.

Historically, this case depicts a general problem faced by breweries prior to the invention of artificial refrigeration, which required them to store their beer in caves, either natural or specially constructed for the aging of beer. Because the temperature of the caves was not always low enough during the summer months, however, ice was also needed. In those days, natural ice cut from rivers and ponds during the winter and stored in insulated icehouses provided the only supply. This explains why breweries initially arose in northern cities like Milwaukee, where ice was readily available during the

\footnotetext{
${ }^{4}$ See, for example, Shavell (1980, 1984), Rogerson (1984), and Edlin and Reichelstein (1996).

547 Mich. 489, 11 N.W. 284 (1882).

${ }^{6}$ The case thus concerned the problem of contract modification (Posner, 1977).

${ }^{7}$ Goebel v. Linn, p. 285.
} 
winter. Still, the market for ice was not dependable because mild winters could cause supply shortages and high prices. Consequently, many large breweries built their own ice houses to store ice so that it was available year round, thus removing at least some of the uncertainty over the cost of beer production (Baron, 1962, pp. 231-234). Smaller breweries like the one in Goebel v. Linn, however, relied on contracts with independent ice companies.

This situation represents a classic problem of organizational choice in which a manufacturer needs to ensure the supply of an input that is essential to its production process. The asset-specificity problem arises because the manufacturer needs to initiate the production process (i.e., the brewing of beer) before the cost of the essential input (ice) can be known with certainty. The question, then, is how to organize the transaction between the manufacturer and the input supplier so as to maximize the gains from trade.

Based on the above framework, there are three options. One is by a spot transaction between the manufacturer and supplier after the cost of the input is realized. The problem with this arrangement is that the input supplier may be in a position to hold up the manufacturer, given that the latter has already made non-salvageable investments that lock it into the transaction. To avoid the holdup problem, the manufacturer, before making any investments, could enter into a contractual arrangement with the supplier that specifies the price of the input. This arrangement reflects the facts of the Goebel v. Linn case. Although the ice company was still able to hold up the brewery for a higher price, the court recognized that the brewery had the option of suing for breach of contract when the ice company initially refused to deliver at the contract price. For some reason, the 
brewery chose not to pursue this remedy, ${ }^{8}$ but if it had, the standard remedy for breach, expectation damages, would have required the ice company to fully compensate brewery for its lost profits. As a final option, the manufacturer could have solved its ice supply problem by simply buying out or merging with the ice company (i.e., vertically integrating). Following this strategy would have ensured the timely delivery of ice at an acceptable cost, but the drawback is the governance cost of managing the ice company, which the model below will treat as an agency cost.

The preceding case study shows the various options that can be used to organize exchange. All are imperfect in their own way, so the optimal choice is the one that maximizes the expected value of the transaction. The model in the next section formalizes the relevant trade-offs.

\section{Analysis of comparative organizational form}

The model in this section asks how the various organizational forms affect incentives for non-salvageable, transaction-specific investments, and for performance, in relation to the hypothetical first-best outcome. The discussion is mostly informal, with the technical details relegated to an appendix. A numerical example will be used to illustrate the key results. For concreteness, I will couch the discussion in terms of the brewery/ice case.

\subsection{Set-up of the model and the social optimum}

Let $V(x)$ be the brewery's gross profit from the sale of beer, where $x$ is its initial investment (i.e., how much beer it brews), and $V^{\prime}>0$, and $V(x)^{\prime \prime}<0$. Storage and sale of

\footnotetext{
${ }^{8}$ It is likely that the brewery did not pursue the damage remedy because it may have bankrupted the ice company (Goebel v. Linn, p. 285). The risk of bankruptcy thus shows that contracts do not completely eliminate the risk of a holdup problem (Miceli, 2002).
} 
the beer, however, requires the delivery of ice at a cost $C$, which is not known with certainty at the time the brewery chooses $x$. The sequence of decisions is therefore crucial: first, the brewery must choose $x$, then the cost of supplying ice is realized, and finally, the decision of whether or not to supply the ice is made. If the ice is delivered, the transaction goes ahead as planned, yielding a social return of $V(x)-C-x$, but if it is not, the initial investment, $x$, is lost.

As usual, the social optimum is derived in reverse sequence of time. Thus, once $C$ has been realized, it is optimal for delivery of the ice to occur if $C \leq V(x)$ for any value of $x$. In contrast, if it turns out that $C>V(x)$, then the ice should not be supplied, even though this means the loss of the brewery's initial investment in beer. Now move back to the time when the brewery has to make its choice of $x$. From a social perspective, it should choose $x$ to maximize the expected value of the beer, subject to uncertainty regarding the delivery of ice. Specifically, because there are some states of the world where the realized cost of ice will make delivery inefficient, the brewer should invest less than if delivery were certain. In other words, the brewer should hedge against the possibility of non-delivery so as to mitigate the amount of the loss in that state.

The actual performance and investment decisions will be made by the relevant decision-makers based on the organizational form governing the "transaction" between the brewer and ice supplier. The next three sections derive the resulting equilibria: first, under a market (spot) transaction, then under a contractual arrangement, and finally under vertical integration.

\subsection{Market transaction}


When the brewery and ice company interact in a market setting, they engage in a spot transaction for the sale of ice after the cost of ice production is realized. I assume that they complete a transaction whenever it is jointly profitable given the realized cost, $C$, and the brewer's prior investment, $x$; that is, whenever $V(x) \geq C$. In other words, I assume Coasian bargaining takes place at this point (Coase, 1960). I further assume that the price of the ice is determined by generalized Nash bargaining. The resulting price is therefore

$$
P=\alpha V(x)+(1-\alpha) C
$$

where $\alpha$ represents the strength of the ice company's bargaining power. ${ }^{9}$ The key thing to note here is that the price is increasing in $x$ as long as $\alpha>0$. Thus, the more that the brewery has invested in reliance on the promised delivery of ice, the higher will be the price that the latter can extract at the time of the transaction. This represents the source of the holdup problem that plagues spot transactions in the presence of prior transactionspecific investments. In particular, because the brewery rationally anticipates the outcome of its subsequent bargaining with the ice company, it will underinvest in beer compared to the efficient level in order to lessen its vulnerability to the holdup problem. This is the primary disadvantage of market exchange in this context.

\subsection{Long-term contract}

As an alternative to engaging in spot transactions, the brewery and ice company may choose to enter into a contract that commits the ice company to deliver ice at a predetermined price over some prescribed time period. The advantage of this arrangement from the brewery's point of view is that it avoids the need for the parties to negotiate a price for each transaction after $C$ has been realized. As a result, it eliminates the holdup

\footnotetext{
${ }^{9}$ In ordinary Nash bargaining where the parties have equal strength, $\alpha=.5$.
} 
problem. In addition, it creates an obligation on the part of the ice company to perform, which the brewery can enforce by legal means. In other words, in those states where the ice company chooses not to perform, the brewery can seek damages in court. (I ignore here the risk of bankruptcy on the part of the input supplier in high cost states.) Let $R$ be the pre-determined contract price, payable on performance, ${ }^{10}$ and let $D$ be the damages in the event of breach as set by the court.

The timing of events in this case is as follows. First, the brewery and the ice company sign the contract and specify the contract price, $R ;{ }^{11}$ then the brewery chooses $x$; and finally, the ice company realizes the cost of performance, $C$, and decides whether or not to perform. In the event where it chooses not to perform, the parties go to court, and court orders the ice company to pay damages of $D$ to the brewery.

Considering first the ice company's performance decision, once $C$ is realized, it will deliver the ice if $R-C \geq-D$, or if

$$
C \leq R+D
$$

and breach if the reverse is true. Recall that the condition for efficient performance, given $x$, is $C \leq V(x)$. Thus, the measure of damages for breach that induces the ice company to perform efficiently is $D=V(x)-R$, which is the "expectation damage" measure (Shavell, 2004, pp. 343-344). Under this measure, the ice company is required to pay the brewery its surplus from the transaction, conditional on its actual level of investment. Expectation damages induces efficient performance because it forces the ice

\footnotetext{
10 The timing of payment is not an essential element of the contract. If the price were payable up-front (fully or partially), then the damage measure would simply be adjusted accordingly. See, for example, White (1988).

${ }^{11}$ I don't formally examine the manner in which the $R$ is determined. Presumably, it reflects the bargaining abilities of the parties before any decisions have been made or costs realized, as opposed to the spot price above, which is negotiated after the brewery has chosen $x$ and the ice company's cost of performance has been revealed. Thus, negotiation over $R$ would not be susceptible to the holdup problem.
} 
company to internalize the full cost of breach to the brewery, given its prior investment of $x$. (Note that such a measure assumes the court is able, after the fact, to observe and condition the amount of damages on the brewery's actual loss of income as a result of the breach; namely, $V(x)$.)

Given the above damage measure, the brewery anticipates that the breach decision will be made efficiently by the ice company for any amount of $x$ that it invests. In other words, the transaction will occur efficiently, as was the case under the spot transaction. The problem, however, is that the brewery now has an incentive to overinvest in beer production. The reason is that the expectation damage measure fully insures it against non-delivery of ice and hence creates a moral hazard problem (Shavell, 1980). ${ }^{12}$ The result here is therefore the opposite of the outcome under market organization, which resulted in underinvestment by the brewery.

\subsection{Vertical integration}

The third alternative to the market or contract is for brewery and ice company to vertically integrate; that is, to organize their transaction within a single firm. For concreteness, I assume that the brewery takes control of ice company, though the reverse is also possible (see, for example, Grossman and Hart, 1986). Thus, I will treat decisions concerning the production and delivery of ice as being made by "employees" of the firm in return for a wage, while the "owner" (the residual claimant) decides how much to invest in brewing the beer. I will model the relationship between the residual claimant and the workers as a principal-agent problem.

\footnotetext{
${ }^{12}$ If the court were able to specify a damage measure based on the efficient (as opposed to the actual) level of the brewery's investment, then it could avoid the moral hazard problem and still induce efficient performance by setting damages equal to $D=V\left(x^{*}\right)-R$. However, we assume that the informational requirements of such a measure are outside of the court's knowledge or ability to learn (Shavell, 2004, pp. 360-361).
} 
The distinguishing feature of this type of organizational form is that it outlives the individual transaction. As a consequence, the employees must be paid in both the delivery and non-delivery states, though I will allow the wages to differ in those states. Specifically, suppose that in the states where the (single) worker is asked to produce and "deliver" ice, he is paid a wage of $w$, but when he is not asked to produce due to high costs, he is paid a wage of $w_{0}$, where $w_{0}$ is defined to be the minimum wage that prevents the worker from quitting (hence, $w \geq w_{0}$ ). In this specification, the cost of delivery, $C$, is interpreted to be the worker's realized, and privately known, cost of performance.

The owner of the integrated firm chooses the maximum cost under which it will produce. Let $\hat{C}$ be this threshold cost level. Thus, the firm will produce when $C \leq \hat{C}$ and not produce when $C>\hat{C}$. However, because the owner cannot observe the realization of $C$, he must create an incentive contract for the employee to produce only in those states where $C \leq \hat{C}$. In other words, the owner must specifies a contract consisting of the wages, $w$ and $w_{0}$, and the threshold cost, $\hat{C}$, to maximize profits, subject to the following constraints

$$
\begin{array}{ll}
w-C \geq w_{0}, & C \leq \hat{C} \\
w-C<w_{0}, & C>\hat{C} .
\end{array}
$$

Constraint (3) says that the worker, after privately observing the cost of production, prefers to produce in the "low cost" state, while (4) says that the worker prefers not to produce in the high cost state but instead to receive the reservation wage. Figure 2 depicts the ranges for $C$ graphically. Note that, given $w_{0}$, which is determined by the next-best option of workers, the choice of $w$ uniquely determines $\hat{C}$ (and vice versa). Thus, only one of these variables needs to be independently chosen. 
[Figure 2 here]

The problem for the owner/brewer is therefore to choose $x$ and $w$ to maximize profit, subject to constraints (3) and (4). It turns out that, in the optimal solution, the firm will underproduce given $x$ - that is, it will take delivery of ice too infrequently from a social point of view. Intuitively, because the brewer/owner cannot observe the worker's cost of delivery, he must pay the worker a high enough wage to produce in the desired range (i.e., when $C \leq \hat{C}$ ). Thus, by reducing the range of production slightly, he can lower the wage he has to pay in production states. (In Figure 2, a reduction in $\hat{C}$ coincides with a lower $w$.) At the optimum, the marginal reduction in the wage bill just equals the lost profit from production. Given the underproduction, however, the firm invests efficiently in $x$ because the owner fully internalizes the cost and benefit of the investment.

\subsection{Comparison of the various forms}

The conclusions from the preceding sections are summarized in Table 1. Note that all of the organizational forms involve some inefficiency: the spot market and longterm contract both result in efficient production (delivery of ice) once the cost of performing is realized, but the brewery invests inefficiently under both. In particular, it underinvests under market exchange in a strategic effort to mitigate the hold-up problem, and it overinvests under the long-term contract due to the moral hazard problem created by the expectation damage measure. In contrast, when the brewery and ice company merge, the integrated firm invests efficiently given the anticipated level of production, but it underproduces as a result of the agency costs associated with the workers' private knowledge of the cost of ice production.

[Table 1 here] 
Since none of the organizational forms achieves the first-best outcome, the choice among them depends on which involves the least distortion. In the context of the current model, this will depend on three factors: (i) the importance of the brewery's up-front investment; (ii) the distribution of production costs (which determines how likely breach is); and (iii) the severity of the hold-up problem (which depends on the relative ex post bargaining strengths of the parties). To illustrate the nature of the choice, I first consider some special cases, and then develop a numerical example.

Suppose first that investment by the brewery in anticipation of performance is not important (i.e., $V$ is fixed). In that case, there is no risk of a holdup, and so both the market and contract yield the efficient (first-best) outcome because they result in efficient production. In contrast, the firm continues to result in underproduction because of the agency costs. Thus, when up-front investments are not important, we would expect spot market transactions and long-term contracts to dominate vertical integration.

Alternatively, suppose that the up-front investments are important but performance is certain. In this case, only the holdup problem remains, so both the contract and firm will yield the efficient outcome, whereas the spot market will continue to result in too little investment.

In the general case where performance is uncertain and investment is important, none of the forms yields the efficient outcome. Thus, all we can say is that, as the likelihood of breach increases, the level of investment under the market more closely tracks the efficient level of investment as compared to the contract. This is true because the level of investment under the contract is not sensitive to the probability of breach, and thus diverges further from the efficient level as that probability increases. In contrast, the 
level of investment under the market, though inefficiently low, at least declines with the probability of breach. Consequently, as the probability of breach increases, the market and firm will tend to dominate the contract, with the choice depending on the relative costs of the hold-up and agency problems.

To gain further insights, we consider a simple example. Let the brewer's gross profit be $V(x)=\theta x^{1 / 3}$, and assume that $C$ is uniformly distributed on [0,4]. A comparison of the various organizational forms involves computing the net value of production under each form while varying the production parameter $\theta$, and the bargaining power parameter $\alpha$. A higher value of $\theta$ implies an increasing probability of performance, while a higher $\alpha$ reflects a more severe holdup problem. Figure 3 shows the optimal form for different combinations of $\theta$ and $\alpha .^{13}$

[Figure 3 here]

Note first that the market dominates for all $\theta$ when $\alpha$ is low (near zero). This is true because the brewery expects to receive a large share of the gains from ex post bargaining and thus internalizes most of the gains from trade. In other words, the holdup problem is not severe. (In the extreme case where $\alpha=0$, the holdup problem is absent and the outcome is first-best under market exchange.) As $\alpha$ rises, however, the holdup problem worsens, and eventually the firm or contract dominates the market, depending on the value of $\theta$. When $\theta$ is high, meaning that the likelihood (and value) of production is high, the contract dominates the firm for reasons noted above. In contrast, when $\theta$ is low, and consequently the likelihood of breach is high, the firm dominates.

\section{Conclusion}

13 The details of the example are available from the author on request. 
The optimal organizational form between two potential trading partners is the one that achieves the largest expected gains from trade. Alternatively stated, it is the form that minimizes the cost associated with inefficient incentives for transaction-specific investments and performance. The contribution of this paper has been to examine markets, firms, and the law as alternative institutional arrangements for organizing transactions in the presence of these imperfections. This exercise represents the logical extension of Coase's seminal contributions to industrial organization on one hand, reflected by his examination of the market-firm boundary; and to law and economics on the other, reflected by his examination of the market-law boundary. The result is a unified approach to comparative organizational form that reveals the relative advantages and disadvantages, within a fairly simple economic setting, of market exchange, court ordering (contracts), and internal governance (agency). 


\section{References}

Baron, S. (1962) Brewed in America: A History of Beer and Ale in the United States, Boston: Little, Brown and Co.

Bolton, P. and M. Dewatripont (2005) Contract Theory, Cambridge, MA: MIT Press,

Calabresi, G. and A. D. Melamed (1972) "Property Rules, Liability Rules, and Inalienability: One View of the Cathedral," Harvard Law Review 85: 1089-1128.

Coase, R. (1960) “The Problem of Social Cost," Journal of Law and Economics 3: 1-44. (1937) “The Nature of the Firm,” Economica 4: 386-405.

Edlin, A. and S. Reichelstein (1996) "Holdups, Standard Breach Remedies, and Optimal Investment," American Economics Review 86: 478-501.

Goldberg, V. (1976) "Regulation and Administered Contracts," Bell Journal of Economics 7: 426-448.

(1985) "Relational Exchange, Contract Law, and the Boomer Problem," Journal of Institutional Economics 144: 100-116.

Grossman, S. and O. Hart (1986) "The Costs and Benefits of Ownership: A Theory of Vertical and Lateral Integration," Journal of Political Economy 94: 691-719.

Hart, O. (2011) "Thinking About the Firm: A Review of Daniel Spulber's The Theory of the Firm," Journal of Economic Literature 49: 101-113.

Hart, O. and J. Moore (1990) "Property Rights and the Nature of the Firm," Journal of Political Economy 98: 1119-1158. 785. (1988) "Incomplete Contracts and Renegotiation," Econometrica 56: 755-

Klein, B., R. Crawford, and A. Alchian (1978) "Vertical Integration, Appropriable Rents, and the Competitive Contracting Process," Journal of Law and Economics 21: 297326.

Miceli, T. (2002) “'Over a Barrel': Contract Modification, Reliance, and Bankruptcy," International Review of Law and Economics 22: 41-51.

Osborne, M. and A. Rubinstein (1990) Bargaining and Markets, San Diego: Academic Press. 
Posner, R. (1977) "Gratuitous Promises in Economics and Law," Journal of Legal Studies 6: 411-426.

Rogerson, W. (1984) "Efficient Reliance and Damage Measures for Breach of Contract," Rand Journal of Economics 15: 39-53.

Segal, I. (1999) "Complexity and Renegotiation: A Foundation for Incomplete Contracts," Review of Economic Studies 66: 57-82.

Shavell, S. (2004) Foundations of Economic Analysis of Law, Cambridge, MA: Belknap Press.

(1984) "The Design of Contracts and Remedies for Breach," Quarterly Journal of Economics 99: 121-148.

(1980) "Damage Measures for Breach of Contract," Bell Journal of Economics 11: 466-490.

White, M. (1988) "Contract Breach and Contract Discharge Due to Impossibility: A Unified Theory," Journal of Legal Studies 17: 353-376.

Williamson, O. (1987) “Transaction Cost Economics," pp. 135-182, in R. Schmalensee and R. Willig, eds., Handbook of Industrial Organization, Amsterdam: NorthHolland.

(1979) "Transaction Cost Economics: The Governance of Contractual Relations," Journal of Law and Economics 22: 233-161.

(1975) Markets and Hierarchies: Analysis and Antitrust Implications, New York: Free Press. 


\section{Appendix}

This appendix provides the formal details of the model described in the text. The notation is as follows:

$V(x)=$ brewer's gross value of performance;

$x=$ brewer's non-salvageable investment in dollars, $V^{\prime}>0, V^{\prime \prime}<0$;

$C=$ random cost of delivering the essential input (ice);

$F(C)=$ distribution function of $C$, where $F^{\prime} \equiv>>0$.

The sequence of events is as follows: first the brewer chooses $x$, then the ice company realizes the value of $C$, and finally, the parties decided whether or not to transact.

The social optimum is found by backwards induction. Thus, once $C$ is realized, it is efficient to transact if and only if $V(x) \geq C$ for any prior choice of $x$. Given this production choice, the expected value of the brewery's investment is given by

$$
\begin{aligned}
& F(V(x)) E[V(x)-C \mid C \leq V(x)]-x \\
= & \int_{0}^{V(x)}[V(x)-C] d F(C)-x .
\end{aligned}
$$

The optimal choice of $x$ therefore solves the following first-order condition

$$
F(V(x)) V^{\prime}(x)-1=0
$$

which says that the brewery should invest up to the point where the expected marginal benefit equals the marginal cost. Let $x^{*}$ denote the resulting first-best level of investment. ${ }^{14}$

The actual performance and investment decisions will depend on the specific organizational form.

Market (spot) transaction. Assuming Coasian bargaining once $C$ is realized, production will occur efficiently given $x$; that is, whenever $V(x) \geq C$. According to the generalized Nash bargaining solution, ${ }^{15}$ the resulting price is given by

$$
P=\alpha V(x)+(1-\alpha) C,
$$

where $\alpha$ represents the strength of the ice company's bargaining power. Given that the brewery rationally anticipates this outcome, it will choose the initial investment to maximize

$$
F(V x) E[V(x)-P \mid C \leq V(x)]-x \text {. }
$$

Using (A3) to substitute for $P$ in this expression yields

\footnotetext{
14 The second-order condition for $x^{*}$ to be a maximum is $F V^{\prime \prime}+F^{\prime}\left(V^{\prime}\right)^{2}<0$, which I assume holds.

${ }^{15}$ See, for example, Osborne and Rubinstein (1990, p. 21).
} 


$$
\begin{aligned}
& F(V(x)) E[V(x)-\alpha V(x)-(1-\alpha) C \mid C \leq V(x)]-x \\
& =\int_{0}^{V(x)}[(1-\alpha)(V(x)-C)] d F(C)-x .
\end{aligned}
$$

The resulting first-order condition is

$$
F(V(x))(1-\alpha) V^{\prime}(x)-1=0
$$

Denote the solution to (A6) by $x_{M}$. Comparing (A6) to (A2) shows that $x_{M}<x *$ for $\alpha>0$. Further, $x_{M}$ is decreasing in $\alpha$, indicating that the brewery invests less as the holdup problem becomes more severe.

Contract. As an alternative to a spot transaction, the brewery and ice company can sign a contract that commits the ice company to deliver ice at a pre-determined price over some prescribed time period. Let $R$ be the price, payable on performance, and let $D$ be the court-awarded damages in the event of breach (non-delivery). The timing of events in this case is as follows. First, the brewery and the ice company sign the contract and specify $R$; then the brewery chooses $x$; and finally, the ice company realizes $C$ and decides whether or not to perform. If it does not perform, the court orders it to pay damages of $D$ to the brewery.

Considering first the ice company's performance decision, once $C$ is realized, it will deliver the ice if and only if $R-C \geq-D$, or if and only if

$$
C \leq R+D
$$

Since the condition for efficient performance, given $x$, is $C \leq V(x)$, the measure of damages for breach that induces the ice company to perform efficiently is $D=V(x)-R$. Given this damage measure, the brewery anticipates that the breach decision will be made efficiently by the ice company for any amount of $x$ that it invests. Thus, it computes its expected return from the contract to be

$$
F(V(x))[V(x)-R]+[1-F(V(x))] D-x .
$$

After substituting $D=V(x)-R$, this expression becomes

$$
V(x)-R-x \text {. }
$$

Thus, the brewery will behave as if performance were certain. Consequently, its profitmaximizing level of investment, denoted $x_{C}$, will solve the first-order condition

$$
V^{\prime}(x)-1=0,
$$

which, given (A2), involves overinvestment.

Vertical integration. The third alternative is for brewery and ice company to vertically integrate; that is, to organize their transaction within a single firm. In the current specification, I assume that the ice company becomes the "employee" (agent) of the brewery, but the brewery (principal) cannot observe the realized cost of production. 
The brewery must therefore structure the wage contract to induce the agent to produce only in the desired (low cost) states. In particular, the contract will specify a threshold $\hat{C}$ such that the agent produces when $C \leq \hat{C}$, for which he receives a wage of $w$, and does not produce when $C>\hat{C}$, for which he receives a wage of $w_{0}$, which is the lowest wage that just prevents him from quitting (the reservation wage). To ensure incentive compatibility, the contract must satisfy the following constraints

$$
\begin{array}{ll}
w-C \geq w_{0}, & C \leq \hat{C} \\
w-C<w_{0}, & C>\hat{C} .
\end{array}
$$

Constraint (A11) says that the worker, after privately observing the cost of production, prefers to produce in the low cost state, while (A12) says that the worker prefers not to produce in the high cost state. Writing equation (A11) as an equality yields the threshold cost as a function of $w$ :

$$
\hat{C}(w)=w-w_{0}
$$

The expected profit for the owner given (A13) is

$$
\int_{0}^{\hat{C}(w)}[V(x)-w] d F(C)-\int_{\hat{C}(w)}^{\infty} w_{0} d F(C)-x
$$

where the first term represents expected profits in the production state, and the second represents costs in the non-production state. The principal chooses $w$ and $x$ to maximize this expression subject to (A13).

Consider first the choice of $w$. The first-order condition is

$$
-F(\hat{C})+\left(V(x)-w+w_{0}\right) f(\hat{C})\left(\frac{\partial \hat{C}}{\partial w}\right)=0
$$

Since $\frac{\partial \hat{C}}{\partial w}=1$ from (A13), this expression can be re-arranged to yield

$$
f(\hat{C})[V(x)-\hat{C}]=F(\hat{C}),
$$

from which it follows that $V(x)>\hat{C}$. Thus, the firm underproduces, given $x$. This is true because, given the principal's inability to observe the realized cost of production, he must pay the worker a high enough wage to induce him to produce over the range where $C \leq \hat{C}$. (See Figure 2.) Thus, by reducing the range of production slightly, he can pay a lower wage in the production states. At the optimum, he just balances the cost of lost production against the lower expected wage bill. The resulting inefficiency represents an agency cost associated with vertical integration. In what follows, let $\widehat{w}(x)$ denote the solution to (A16).

The principal's optimal investment, $x$, solves the following first-order condition 


$$
\int_{0}^{\hat{C}} V^{\prime}(x) d F(C)-1-F(\hat{C})\left(\frac{\partial \widehat{w}}{\partial x}\right)+\left[V(x)-\widehat{w}(x)+w_{0}\right] f(\hat{C})\left(\frac{\partial \widehat{w}}{\partial x}\right)=0 .(\mathrm{A} 17)
$$

Since the final two terms drop out by (A13) and (A16), we have

$$
F(\hat{C}) V^{\prime}(x)-1=0
$$

Thus, the owner invests optimally, given the cost threshold $\hat{C}$. 
Table 1. Outcomes under the various organizational forms.

\begin{tabular}{lll}
\hline Organizational form & Production decision & Investment decision \\
Market & Efficient & Under-invest \\
Contract & Efficient & Over-invest \\
Firm & Under-produce & Efficient \\
\hline
\end{tabular}




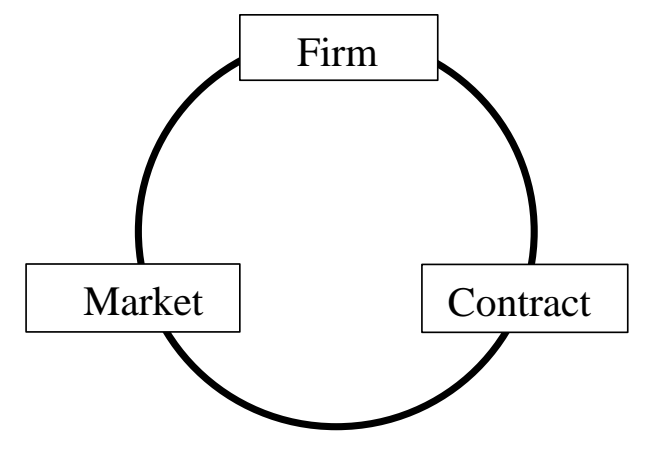

Figure 1. Coasian framework for organizational choice 


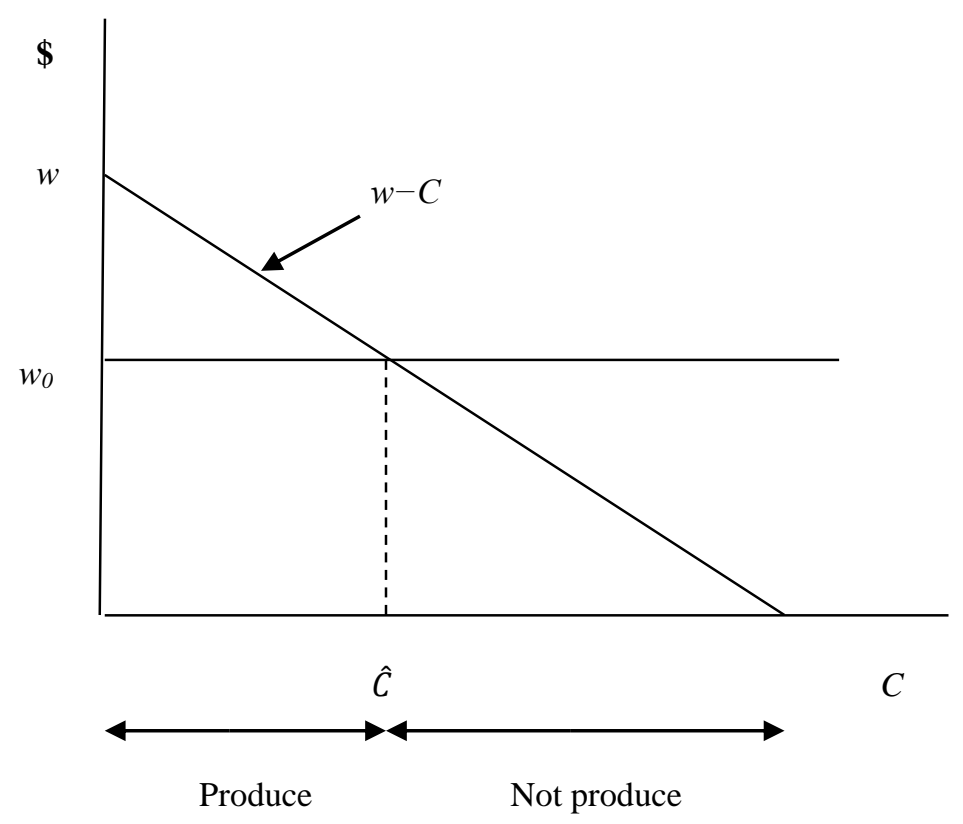

Figure 2. Ranges for production and non-production under vertical integration. 


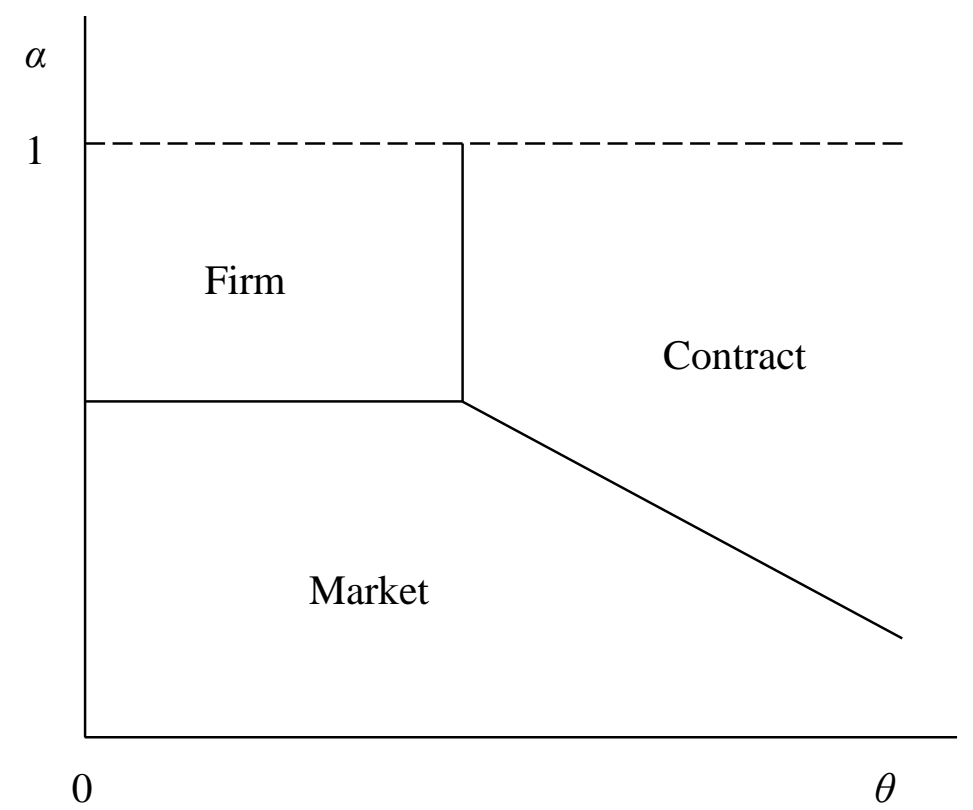

Figure 3. Regions where different organizational forms dominate. 